\title{
Dynamic response control of structures using liquid column vibration absorber: an experimental study
}

\author{
Supradip Saha ${ }^{1} \cdot$ Rama Debbarma $^{1}$
}

Received: 8 April 2016/ Accepted: 5 July 2017/Published online: 13 July 2017

(C) The Author(s) 2017. This article is an open access publication

\begin{abstract}
The performance and effectiveness of the liquid column vibration absorber (LCVA) in controlling the vibration of structures have been investigated in this paper. To evaluate the performance of LCVA system in mitigating the structural response under dynamic loading (i.e. harmonic excitation), a set of experiments are conducted on a scaled model of steel structure-LCVA system. LCVA have non-uniform cross-sectional dimensions of the horizontal and vertical columns whereas Tuned Liquid Column Damper (TLCD) carries same cross-sectional dimensions. For conducting a comparative study, same experiments were performed for TLCD also. Several excitation frequency ratios (0.5-2.0) and various mass ratios (5-7.5\%) are considered in this study. The parameter, tuning ratio considered for all of the experiments is 1.0. The effectiveness of the LCVA and TLCD is measured based on the response reduction of the structure. From the experimental results, it is observed that LCVA has better performance in controlling the structural response.
\end{abstract}

Keywords Liquid column vibration absorber - Tuned liquid column damper · Vibration control · Excitation frequency ratio $\cdot$ Mass ratio

Rama Debbarma

ramadebbarma@gmail.com

1 Department of Civil Engineering, National Institute of Technology Agartala, Barjala, Jirania, Tripura (West) 799046, India

\section{Introduction}

In this modern age of life, as a result of the shortage in land space accessibility especially within the urban areas and due to the implementation of modern construction techniques have caused an increased presence of skyscraper structures. These skyscrapers structures are flexible, comparatively light-in-weight and gently damped, usually leading to very little structural damping and low natural frequencies. They can easily sustain the transverse loads, but whenever they subjected to structural vibrations caused due to the dynamic loads (e.g. wind or earthquake); they undergo vital vibrations which can become unacceptable from the perspective of serviceability and safety. In last few decades, world has experienced several devastating earthquakes, leading to increased loss of human life due to collapse of buildings and severe structural damages. Therefore, to avoid the structural and non-structural damages, structural engineers are operating to work out different kinds of structural systems that are robust and can withstand strong motions. The installation of some kinds of vibration absorber systems can also be implemented into those tall buildings to mitigate the damaging effects of such dynamic forces, which can work by absorbing or reflecting a portion of the input energy that might rather be transmitted to the structure itself. The vibration control systems are classified as Passive, Active, Semi-active and Hybrid. In this present paper, the study is focused basically on dynamic response control of structures using passive vibration control devices named liquid column vibration absorber (LCVA) and tuned liquid column damper (TLCD). The tuned liquid column dampers are a special type of tuned liquid damper (TLD) used for controlling vibration of structure under various dynamic loading composed of two vertical columns of liquid connected by a 
horizontal crossover duct of the same width, enclosed in a custom U-shaped container. It basically dissipates the structural vibration energy by combined action of the movement of the liquid mass present in the U-shaped container, the restoring force on that liquid due to the gravity and also due to the damping effect due to orifice. A particular type of TLCD is called LCVA, whose horizontal cross-sectional area is different than that of the vertical section. Advantages of TLCD and LCVA are greater compared to other passive vibration control devices like tuned mass dampers (TMD), Fluid viscous dampers, Viscoelastic dampers, Friction dampers, etc. because of their lower cost, easy installation in the existing structure, easier handling and few maintenance requirements. Since water is used as the liquid in the TLCD and LCVA, as a result they may be used for water supply and as well as for fire fighting.

In recent past, several studies have been undertaken for the purpose of controlling vibrations. Among them, Sakai et al. (1989) were the first to propose tuned liquid column damper (TLCD), which is used to reduce wind-induced horizontal loads of tall structures. Later on, Balendra et al. (1995) studied the effectiveness of TLCDs in controlling the wind-induced vibration of towers. Gao et al. (1997) studied the effectiveness of U-shaped as well as V-shaped tuned liquid column damper (TLCD) in controlling structural vibration under dynamic loading. Also, Gao et al. (1999) conducted the parametric study on multiple tuned liquid column dampers (MTLCDs) to determine the characteristics of the MTLCD in suppressing structural vibration. Sadek et al. (1998) presented the design parameters for single and multiple tuned liquid column dampers for reducing the response of structures to seismic excitations, whereas Balendra et al. (1999) investigated the effectiveness of the TLCD in reducing the along-wind response of tall buildings. The optimisation of TLCD and LCVA parameters to minimise the vibration effect of structure under random earthquake load considering uncertain but bounded (UBB) type and uncertain random system parameters was proposed by Debbarma et al. (2010) and Chakraborty and Debbarma (2011). Chakraborty and Debbarma (2015) obtained optimum parameter of TLCD considering system parameters as bounded type under earthquake load by Robust Design Optimisation (RDO) method. Chang and Hsu (1998) derived an unsteady and non-uniform flow equation while studying the performance and effectiveness of an LCVA in controlling the windinduced vibration of a building. Hitchock et al. (1997a, b) at first investigated the effects of the geometric configuration of LCVAs without orifices and later by performing experiments observed the characteristics of rectangularbased bidirectional LCVAs (without orifices). Bhattacharjee et al. (2013) investigated the performance of unidirectional single TLD to change the dynamic characteristics of the structure, while Saha and Debbarma (2015) performed an experimental investigation on a TLCD scale model attached to a steel structure which is subjected to harmonic excitation.

The objective of this present study is to mitigate the response of the structure by means of installing LCVA model to the steel structure model subjected to sinusoidal external motion as well as to evaluate the effect of different parameters such as excitation frequency ratio, mass ratio, etc., on the performance of the damper system and to conduct a comparative study with TLCD model.

\section{Equation of motion}

The equation of motion of the liquid column vibration absorber proposed by Chakraborty and Debbarma (2011) is

$\rho \mathrm{A}_{\mathrm{h}} L_{\mathrm{e}} \ddot{y}+\frac{1}{2} \rho \mathrm{A}_{\mathrm{h}} \xi|\dot{y}| \dot{y}+2 \rho \mathrm{g} A_{\mathrm{h}} y=-\rho A_{\mathrm{h}} B_{\mathrm{h}}\left(\ddot{x}+\ddot{z}_{\mathrm{b}}\right)$

where $y$ is the displacement of the liquid due to the horizontal motion $x$ of the tube, $\ddot{z}_{\mathrm{b}}$ is the base acceleration of the structure-damper system due to earthquake motion, $\xi$ is the coefficient of head loss controlled by the opening ratio of the orifice typically placed at the centre of the horizontal portion of the damper, $L_{\mathrm{e}}$ is the length of the liquid measured along the centreline of the tube, $A_{\mathrm{h}}$ is the crosssectional area of the tube, $B_{\mathrm{h}}$ is the horizontal width of the tube, $\rho$ is the density of the liquid and $g$ is the acceleration due to gravity. This equation is non-linear in nature due to the presence of the liquid damping. In the present study, the equivalent linearization technique has been used and Eq. (1) is approximated as:

$\rho A_{\mathrm{h}} L_{\mathrm{e}} \ddot{y}+2 \rho A_{\mathrm{h}} C_{\mathrm{p}} \dot{y}+2 \rho A_{\mathrm{h}} \mathrm{gy}=-\rho A_{\mathrm{h}} B_{\mathrm{h}}\left(\ddot{x}+\ddot{z}_{\mathrm{b}}\right)$

in which $C_{\mathrm{p}}$ represents the equivalent linearization damping coefficient and can be expressed as $C_{\mathrm{p}}=\frac{\sigma_{\dot{y}} \xi r}{\sqrt{2 \pi}}$ where $\sigma_{\dot{y}}$ is the standard deviation of the liquid velocity. The natural frequency of the damper is given by $\omega_{\mathrm{d}}=\sqrt{2 \mathrm{~g} / \mathrm{Le}}$ and the natural period $T_{\mathrm{d}}=\frac{2 \pi}{\omega \mathrm{d}}$, where $g$ is the gravitational acceleration in $\mathrm{m} / \mathrm{s}^{2}, L_{\mathrm{e}}$ is the effective length of LCVA in $\mathrm{m}$, which is expressed as $L_{\mathrm{e}}=L[1-p(r-1)]$, where $\mathrm{p}$ is the length ratio and $\mathrm{r}$ is the area ratio. $L=B_{\mathrm{h}}+2 h$, where $h$ is vertical height of the liquid in the damper system.

The excitation frequency ratio $\left(\omega / \omega_{\mathrm{s}}\right)$ is the ratio of the excitation frequency to the structural natural frequency $\left(\omega_{\mathrm{s}}\right)$ which is controlled by varying external frequencies. The mass ratio $(\mu)$ is the ratio of the mass of the damper $\left(m_{\mathrm{d}}\right)$ to the mass of the structure $\left(m_{\mathrm{s}}\right)$. The length ratio $(p)$ of liquid column damper is the ratio of the width of the horizontal portion (B) to the effective length of the damper 
$\left(L_{\mathrm{e}}\right)$. The tuning ratio $(\gamma)$ is the ratio of the natural frequency of the damper $\left(\omega_{\mathrm{d}}\right)$ to the natural frequency of the structure $\left(\omega_{\mathrm{s}}\right)$. The area ratio $(r)$ is the ratio of the vertical $\left(A_{\mathrm{v}}\right)$ to the horizontal column $\left(A_{\mathrm{h}}\right)$ cross-sectional areas, i.e. $r=\frac{A_{\mathrm{v}}}{A_{\mathrm{h}}}$.

\section{Experimental setup}

The arrangement of the steel structure model over the shake table along with the LCVA model is shown in Fig. 1. The shake table, which is unidirectional in nature, will impose horizontal motion to the structure.

Various specifications of the shake table:

- Size of the shake table: $1 \mathrm{~m} \times 1 \mathrm{~m}$.

- Weight of the shake table: $100 \mathrm{~kg}$ (approximately).

- Range of maximum displacement: $\pm 100 \mathrm{~mm}$.

- Maximum operating frequency: $0-10 \mathrm{~Hz}$.

- Device required for applying operating frequency: microprocessor-based three-phase precision AC drive.

Various specifications of the steel structure model:

- Description of the structure model: the steel structure model has a mild steel plate of thickness $10 \mathrm{~mm}$ so that it acts as a rigid slab of a structure. The load of the slab is transferred first into the beams then into the columns. There are four number of beams and columns of size $10 \mathrm{~mm} \times 10 \mathrm{~mm} \times 500 \mathrm{~mm}$, i.e. there are four nos. of beams used in this structure to carry the imposed load from the steel plate which is then transferred to the base by means of another four columns and the crosssectional area of these beams and columns are $10 \mathrm{~mm} \times 10 \mathrm{~mm}$, i.e. width $10 \mathrm{~mm}$ and thickness $10 \mathrm{~mm}$ while the length of both the beams and columns are equals to $500 \mathrm{~mm}$. The bars used for beams and columns are solid square bars.

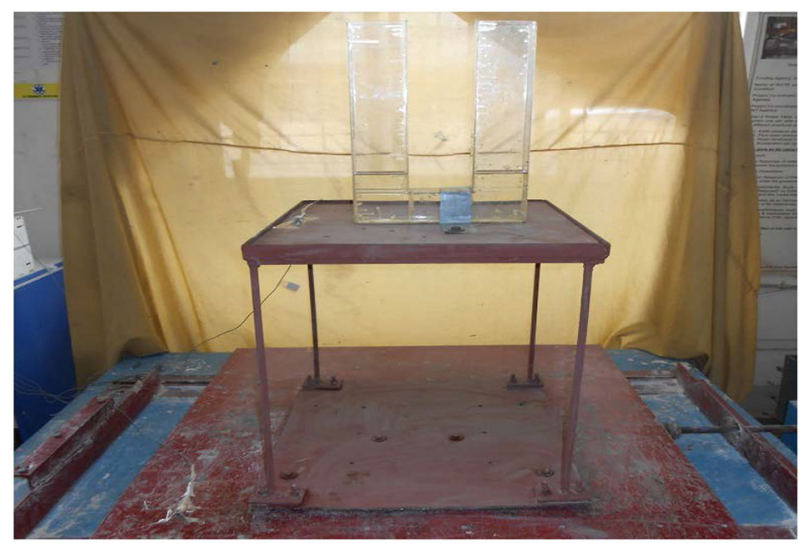

Fig. 1 LCVA-Structure Experimental setup
- The thickness of the steel plate used at top of the structure is $10 \mathrm{~mm}$.

- The columns are connected to beams and the base plate while the beams are connected to the slab by welding.

- Natural frequency of the structure model: $7.7 \mathrm{rad} / \mathrm{s}$ (or, $1.237 \mathrm{~Hz}$ ).

- Time period of the structure: $0.808 \mathrm{~s}$.

Various specifications of the LCVA experiment:

- Description of the LCVA model: the LCVA consists of one horizontal crossover duct along with two vertical columns having different cross-section than the horizontal one. It is made up of glass fibre sheet of thickness $2 \mathrm{~mm}$. The cross-section of the horizontal tube is of 6 sq. $\mathrm{cm}$, whereas for column it is $9 \mathrm{~cm} \times 6 \mathrm{~cm}$. The bottom width of the model is kept equal to $29.2 \mathrm{~cm}$.

- Area ratio $(r): 1.5$

- Instrument used in the experiments: Brüel and Kjær Deltatron 4507-01 accelerometer placed at the top and bottom of the structure.

Various specifications of the TLCD experiment:

- Description of the TLCD model: The TLCD model is made up of glass fibre sheet of $2 \mathrm{~mm}$ thickness. It consists of one horizontal tube along with two vertical columns having same cross-section. Both the horizontal tube and vertical columns have a cross-section of $6.44 \mathrm{~cm}^{2}$, while the bottom width of the model is $29.2 \mathrm{~cm}$.

- Area ratio $(r): 1.0$

- Instrument used in the experiments: Accelerometer, which measures the acceleration and linear variable differential transformer (LVDT), which measures the displacement of the structure positioned at the base and top.

The motion imposed on the structure is harmonic in nature, with control over the frequency of the oscillations. The measured response parameters are acceleration and displacement of the structure along the line of action of the force. In case of the TLCD-Structure system, the acceleration and displacement response is measured by attaching accelerometers and LVDTs at the base and top of the structure. TRIMEX Acquire data acquisition system is used to acquire and analyse the experimental data with the help of accelerometer interface unit, dynamic LVDT signal conditioner (Model: 2000-C-16) and Dynamic Strain Measurement system (32 channels). While in case of the LCVA-Structure system, those responses have been measured by attaching Brüel and Kjær Deltatron 4507-01 accelerometers (Brüel and Kjær Sound and Vibration Measurement A/S, Nærum, Denmark) at the base and top of the structure model. PULSE 3560B computerised data 
acquisition and multi-analyser system are used to acquire and analyse the data obtained in the experiments. In each set of the experiments, the Damper-Structure system is subjected to harmonic sinusoidal base motions. This external motion imposed to the structure by means of an induction motor mounted on the shake table. To maintain this external excitation amplitude constant, the displacement of the shake table has been kept constant. The direction of the imposed force (or acceleration) is the plane parallel to the direction of the horizontal tube of the LCVA and TLCD damping device. The damping devices are connected rigidly with the structure by means of clamps fitted with screws at the top of the structure and the dampers are installed at the Centre of Gravity point of the plan of the structure

\section{Selection of TLCD and LCVA parameters}

The response of the steel structure model attached separately with TLCD and LCVA and subjected to a base excitation will mainly depend on the characteristics of the TLCD-structure system and LCVA-structure system. A Damper (TLCD or LCVA) may be considered as properly designed if it reduces the structure's motion for a particular base excitation for a given set of values of excitation frequency ratios $\left(\omega / \omega_{\mathrm{s}}\right)$, several mass ratios $(\mu)$, etc. of the liquid column. In both the experimental cases of TLCD and LCVA, the liquid used inside the devices is water (Tables 1,2).

\section{Results and discussion}

Investigations are conducted to study the dynamic behaviour of the structure with LCVA and with TLCD, when it is subjected to harmonic base motion applied to the shake table. The harmonic ground motion is defined by its excitation frequency and amplitude ground motion. In this present study, displacement and acceleration of the structure with and without the damping system (TLCD/LCVA) are measured by attaching LVDTs and accelerometers and data acquisition system, considering different excitation frequency ratios and mass ratios. The experimental data related to the TLCD system are considered from Saha and Debbarma (2015). The results obtained from this experimental study have been discussed and compared thereafter.

\section{Effect of various external frequencies on structural response}

The effect of various excitation frequency ratios on the responses of structure for mass ratio $\mu=5 \%$ and length ratio $p=0.7$ has been shown in Figs. 2 and 3, for displacement and acceleration, respectively. Various external excitation frequency ratios ranging from 0.5 to 2.0 are considered in this experimental study and the corresponding maximum structural response has been observed. It can be easily observed that at the region of resonance $(\omega /$ $\left.\omega_{\mathrm{s}}=1\right)$, the response amplitude reduces significantly due to the attachment of the damper. Thus, the maximum reduction of response is obtained when the structure is subjected to resonant frequency. The obtained reduction is 41.066 and $41.509 \%$ for displacement and acceleration, respectively, when TLCD was installed, whereas in case of LCVA, these responses reduced to 55.709 and $52.439 \%$. Hence, from these observations, it is clear that the maximum reduction in response is obtained when the frequency ratio becomes unity.

\section{Variation of structural responses with time histories}

Typical plots of the variation displacement and acceleration time histories of the structure with and without

Table 1 Experimental cases

\begin{tabular}{llllll}
\hline Model & Mass ratio $(\mu)$ & Area ratio $(r)$ & Length ratio $(p)$ & External frequency $(\omega)$ in $\mathrm{Hz}$ & External frequency ratio $\left(\omega / \omega_{\mathrm{s}}\right)$ \\
\hline LCVA & $5 \%$ & 1.5 & 0.7 & $0.613,0.919,1.229,1.532,1.839,2.146,2.45$ & $0.5,0.75,1.0,1.25,1.50,1.75,2.0$ \\
TLCD & $5 \%$ & 1.0 & 0.7 & $0.613,0.919,1.229,1.532,1.839,2.146,2.45$ & $0.5,0.75,1.0,1.25,1.50,1.75,2.0$ \\
\hline
\end{tabular}

Table 2 Height of liquid inside the column sections

\begin{tabular}{llll}
\hline Mass ratio $(\mu)(\%)$ & Width of the horizontal tube $(\mathrm{H})$ in $\mathrm{cm}$ & \multicolumn{2}{l}{ Height of liquid $(\mathrm{h})$ in column in $\mathrm{cm}$} \\
\cline { 3 - 4 } & & TLCD & LCVA \\
\hline 5 & 22.75 & 1.655 & 1.917 \\
6 & 22.75 & 4.935 & 4.416 \\
7 & 22.75 & 8.190 & 6.916 \\
7.5 & 22.75 & 9.820 & 8.167 \\
\hline
\end{tabular}




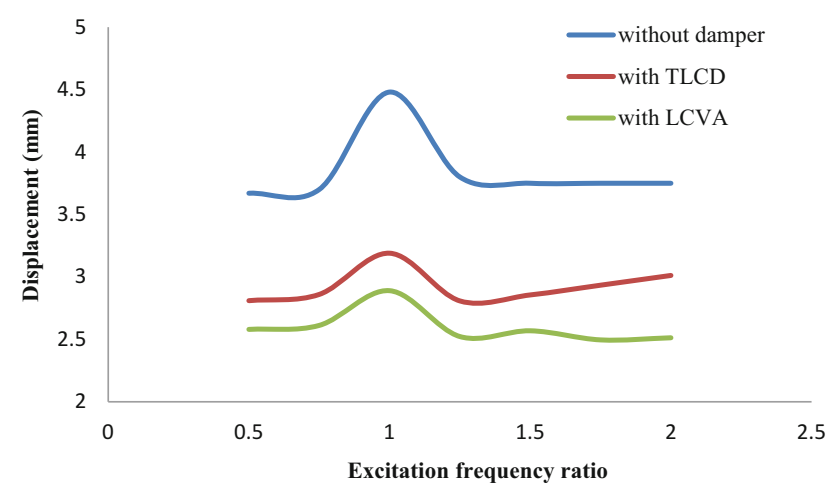

Fig. 2 Variation of displacement of structure with various excitation frequency ratios considering mass ratio $\mu=5 \%$ and length ratio $p=0.7$

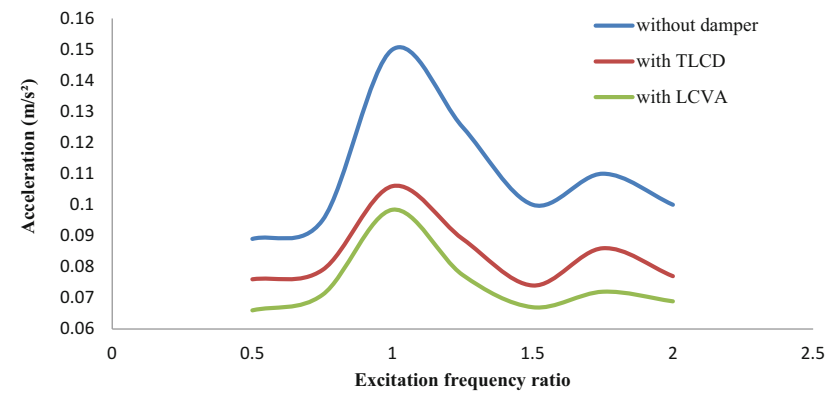

Fig. 3 Variation of acceleration of the structure with various excitation frequency ratio considering mass ratio $\mu=5 \%$ and length ratio $p=0.7$ dampers for excitation frequency ratio $\omega / \omega_{\mathrm{s}}=1$, mass ratio $\mu=5 \%$, tuning ratio $\gamma=1$ and length ratio $p=0.7$ have been shown in Figs. 4 and 5. In these cases, the responses at the top of the structure have been observed. From Fig. 4, it is seen that the maximum displacement of the structure without any damper is as about $4.129 \mathrm{~mm}$, which is reduced to about 3.404 and $2.548 \mathrm{~mm}$ with the installation of TLCD and LCVA, respectively. Similarly, Fig. 5 shows the acceleration response reduction due to the implementation of the respective damper system. Therefore, it can be easily observed from these graphical representations that with the implementation of LCVA, the responses reduced more compared to the reduction effect of TLCD.

\section{Effect of various mass ratios on structural response}

Different mass ratios $(\mu)$, varying from 5 to $7.5 \%$, are considered here to study the effect of various liquid masses present in the TLCD and LCVA systems and corresponding plots of displacement and acceleration time histories of the steel structure model for resonance condition, i.e. $\omega / \omega_{\mathrm{s}}=1$ are shown in Figs. 6, 7, 8, 9 . With the help of the mentioned observations, it is clear that the optimum control of peak responses for a particular frequency ratio is obtained with higher values of mass ratios.
Fig. 4 Variation of displacement of structure with time (with and without damper) for mass ratio $\mu=5 \%$, excitation frequency ratio $\omega /$ $\omega_{\mathrm{s}}=1$, tuning ratio $\gamma=1$ and length ratio $p=0.7$

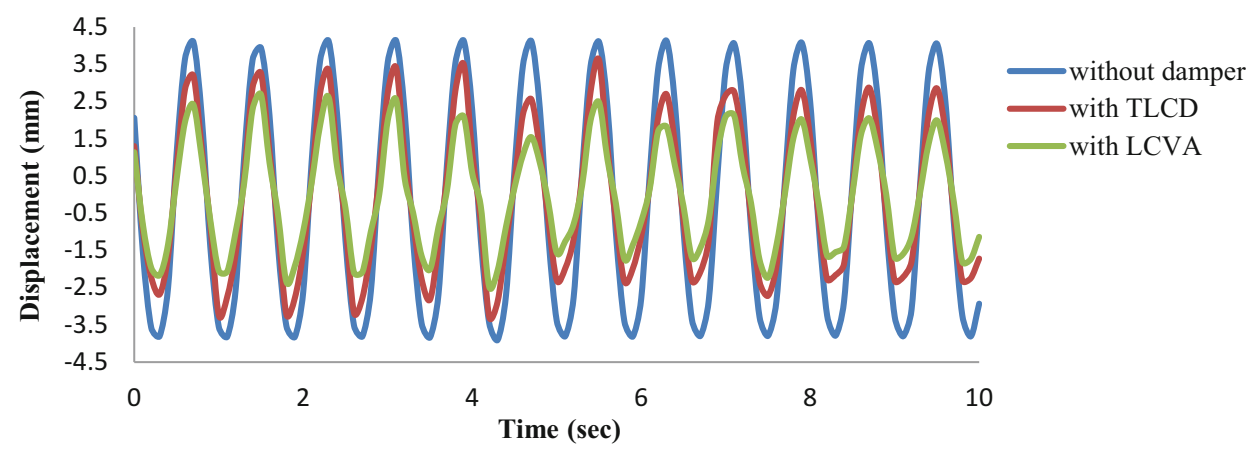

Fig. 5 Variation of acceleration of structure with time (with and without damper) for mass ratio $\mu=5 \%$, excitation frequency ratio $\omega / \omega_{\mathrm{s}}=1$, tuning ratio $\gamma=1$ and length ratio $p=0.7$

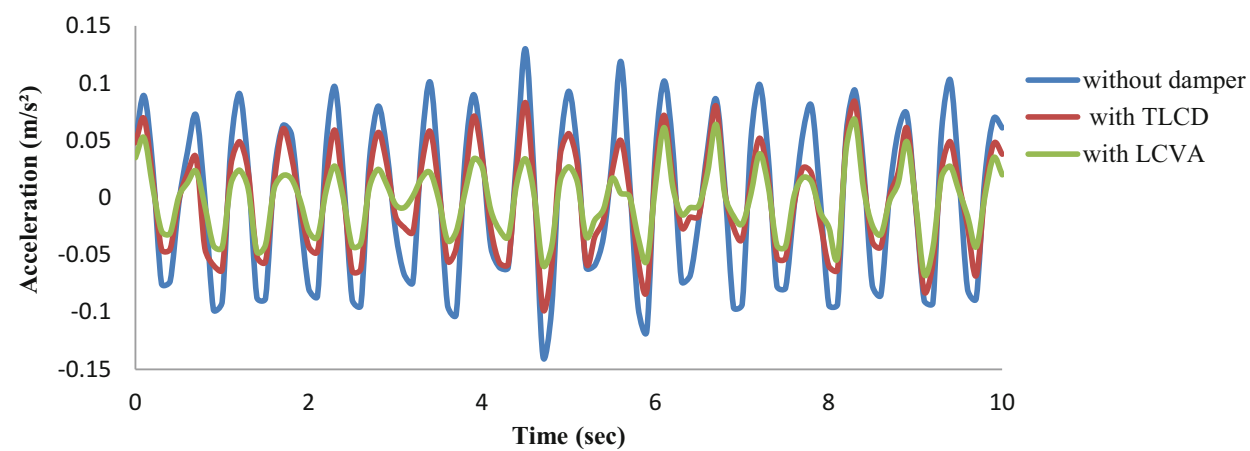


Fig. 6 Variation of displacement of structure attached with TLCD with time for various mass ratios considering excitation frequency ratio $\omega / \omega_{\mathrm{s}}=1$

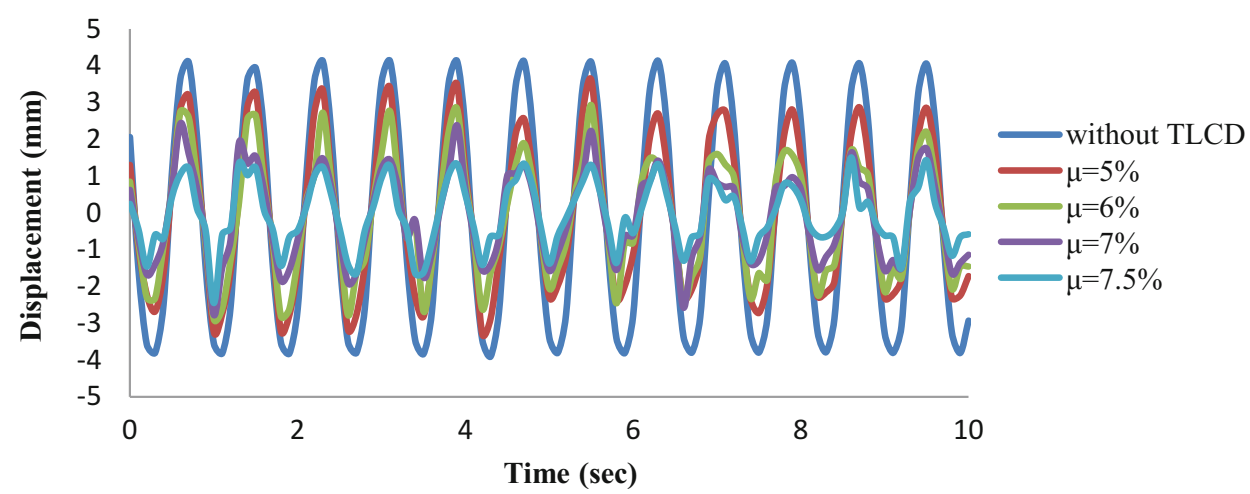

Fig. 7 Variation of

displacement of structure attached with LCVA with time for various mass ratios considering excitation frequency ratio $\omega / \omega_{\mathrm{s}}=1$
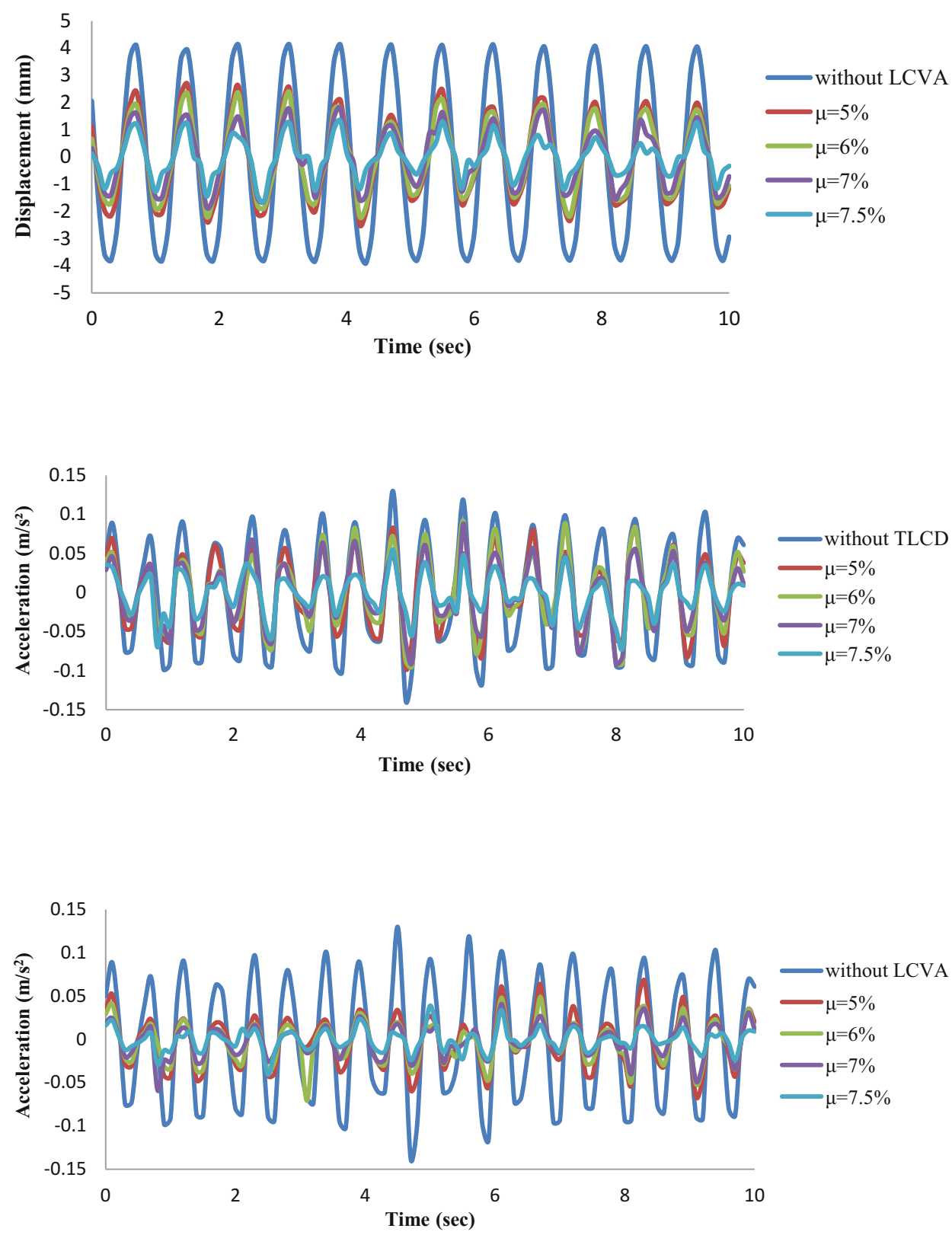


\section{Effectiveness of the dampers}

The effectiveness of the damper (TLCD or LCVA) is calculated in terms of the reduction of structural displacement or acceleration with damper compared to the corresponding value without damper.

Effectiveness of the TLCD $=\left(\frac{x_{S}-x_{T}}{x_{T}} \times 100\right) \%$

Effectiveness of the LCVA $=\left(\frac{x_{S}-x_{L}}{x_{L}} \times 100\right) \%$

where $x_{\mathrm{s}}$ is the peak response (displacement or acceleration) values of structure without any damping system; $x_{\mathrm{T}}$ and $x_{\mathrm{L}}$ are the peak responses of structure attached with the TLCD system and LCVA system, respectively. The effectiveness of the TLCD found here is 41.066 and $41.509 \%$ in reducing the displacement and acceleration of the structure system, whereas for the LCVA those responses reduced up to 55.709 and $52.439 \%$, respectively, at the tuned condition as well as at the resonance region.

\section{Conclusions}

The performance of an LCVA has been investigated in this present study for the mitigation of structural response. The experimental results are compared with the results obtained by installing a TLCD to evaluate the effectiveness of the damper system. These damper systems were separately mounted over the steel structure model and a set of experiments were carried out for studying the behaviour of them under harmonic loading condition. Several excitation frequency ratios varying from 0.5 to 2.0 and various mass ratios varying from 5 to $7.5 \%$ were considered. The effect of resonance as well as tuned condition $\left(\omega_{\mathrm{d}} / \omega_{\mathrm{s}}=1\right)$ on the structural response is also noticed. The responses of with and without damping system are evaluated and presented in the graphical form. It has been observed that maximum reduction of the structural responses occurs at the region of resonance. For the tuned condition at resonance frequency, the effectiveness of TLCD has been found as $41.066 \%$ for displacement and $41.509 \%$ for acceleration response. LCVA also performed under the same conditions and reduces the displacement about $55.709 \%$ and acceleration about $52.439 \%$. From this experimental study, it has been found that LCVA and TLCD can successfully mitigate the response of the structure. But it can be concluded that
LCVA has better efficiency in reducing the responses than TLCD.

Open Access This article is distributed under the terms of the Creative Commons Attribution 4.0 International License (http://crea tivecommons.org/licenses/by/4.0/), which permits unrestricted use, distribution, and reproduction in any medium, provided you give appropriate credit to the original author(s) and the source, provide a link to the Creative Commons license, and indicate if changes were made.

\section{References}

Balendra T, Wang CM, Cheong HF (1995) Effectiveness of tuned liquid column dampers for vibration of towers. Eng Struct 17(9):668-675

Balendra T, Wang CM, Rakesh G (1999) Vibration control of various types of buildings using TLCD. J Wind Eng Ind Aerodyn 83:197-208

Bhattacharjee E, Halder L, Sharma RP (2013) An experimental study on tuned liquid damper for mitigation of structural response. International Journal of Advanced Structural Engineering, 5(3)

Chakraborty S, Debbarma R (2011) Stochastic earthquake response control of structures by liquid column vibration absorber with uncertain bounded system parameters. Struct Saf 33:136-144

Chakraborty S, Debbarma R (2015) Robust optimum design of tuned liquid column damper in seismic vibration control of structures under uncertain bounded system parameters. Struct Infrastruct Eng (Taylor and Francis). doi:10.1080/15732479.2015.1031142

Chang CC, Hsu CT (1998) Control performance of liquid column vibration absorbers. Eng Struct 20(7):580-586

Debbarma R, Chakraborty S, Ghosh SK (2010) Optimum design of tuned liquid column dampers under stochastic earthquake load considering uncertain bounded system parameters. Int J Mech Sci 52:1385-1393

Gao H, Kowk KCS, Samali B (1997) Optimization of tuned liquid column dampers. Eng Struct 19(6):476-486

Gao H, Kowk KCS, Samali B (1999) Characteristics of multiple tuned liquid column dampers in suppressing structural vibration. Eng Struct 21:316-331

Hitchock PA, Kwok KCS, Watkins RD, Samali B (1997a) Characteristics of liquid column vibration absorbers (LCVA)-I. Eng Struct 19(2):126-134

Hitchock PA, Kwok KCS, Watkins RD, Samali B (1997b) Characteristics of liquid column vibration absorbers (LCVA)—II. Eng Struct 19(2):135-144

Sadek F, Mohraz B, Lew HS (1998) Single and Multiple tuned column dampers for seismic applications. Earthq Eng Struct Dynam 27:439-463

Saha S, Debbarma R (2015) An experimental investigation on dynamic response control of structures using tuned liquid column damper. Int J Eng Technol Manag Appl Sci (IJETMAS) 3:181-187

Sakai F, Takaeda S, Tamaki T (1989) Tuned liquid column dampernew type device for suppression of building vibration. Proceedings of the International Conference on High-rise Building, Nanjing, China, pp 926-931 